\title{
Does information change attitudes? The case of restoration of indigenous fishery in Dal Lake, Kashmir, India
}

\author{
NEHA W. QURESHI ${ }^{1}$, M. KRISHNAN ${ }^{2}$, S. A. WANI ${ }^{3}$, V. RAMASUBRAMANIAN ${ }^{1}$, \\ N. SIVARAMANE ${ }^{2}$ AND C. SUNDARAMOORTHY ${ }^{4}$ \\ ${ }^{1}$ ICAR-Central Institute of Fisheries Education, Mumbai - 400 061, Maharashtra, India \\ ${ }^{2}$ ICAR-National Academy of Agricultural Research Management (NAARM), Rajendernagar, Hyderabad - 500030 \\ Telangana, India \\ ${ }^{3}$ Sher-e-Kashmir University of Agricultural Sciences and Technology, Kashmir (SKUAST-K), Srinagar - 191121 \\ Jammu Kashmir, India \\ ${ }^{4}$ ICAR-Central Institute for Research on Cotton Technology, Matunga, Mumbai - 400 019, Maharashtra, India \\ e-mail: mkrishnan57@gmail.com
}

\begin{abstract}
This paper is an attempt to understand the impact of two sided information on stakeholders related to common use resources. Data were collected from key stakeholder groups on influence of information on attitude towards restoration of indigenous fishery of Schizothorax in Dal Lake. The main objectives of this research were to evaluate what impact a two-sided information on the potential advantages and disadvantages of Schizothorax restoration has, on attitudes towards its restoration and how prior familiarity with the issue abates the effect of information. The results from the study revealed that two-sided information had a positive effect on attitudes towards restoration of Schizothorax fishery at all levels of stakeholders except consumers whose awareness were already high. Further, the positive effect of information seemed much greater for fishers who were unsure and unfamiliar with the issue than those who were familiar. Results also revealed that fishers who are the primary stakeholders of the lake held a very positive attitude towards restoration of Schizothorax fishery in the lake than consumers since they were only concerned with fisheries. Effective communication is very important between the institutions concerned with restoration of Schizothorax fishery and specific stakeholder groups.
\end{abstract}

Keywords: Attitudes, Dal Lake, Information, Kashmir, Schizothorax fishery

\section{Introduction}

The Dal Lake is one of the major tourist attractions located in the heart of Srinagar City in Kashmir, India and now has earned status of one of the hyper eutrophic urban lakes of the world. The fishery of the lake has been on the decline since last two decades, especially that of the local endemic genus Schizothorax. The catch is dominated by carps which now contributes substantially (above 70\%) towards the fish basket of Srinagar City. The Schizothorax genus consists of almost six species and among the six, three are found in Dal Lake. These cyprinids require very clean and pristine environment for growing and breeding, but owing to the high levels of pollution and dominance of carps in the Dal Lake, these fishes have declined drastically and are now on the verge of extinction (Naik et al., 2015).

In order to elicit responses with respect to the importance of the issue of sustainability and restoration of Schizothorax species, a two sided questionnaire was used. Qureshi (2013) had used Contingent Valuation
(CV) to assess the sustainability issue and the restoration of Schizothorax fishery. But the disadvantage of CV was that the responses were not based on knowledge gained post-briefing, but was a spontaneous response based on the assumptions that the respondents ( 8 sets of respondents) were well informed about the issue. There is a need to educate the identified respondents in respect of the issues involved around the core issue and then seek their willingness to pay (WTP). This would ensure elimination of bias in knowledge levels and recording of responses in a two way question mode. Here, the stakeholders (fishers of Dal Lake and fish consumers in Srinagar) were given two sided information specifically designed to capture the sentiments of the two sets of respondents.

This study tried to assess impact, if any, of two-sided information on potential advantages and disadvantages of Schizothorax restoration has on stakeholder attitudes towards Schizothorax restoration and how prior familiarity with issue of pollution and other anthropogenic activities laid emphasis on tourism, abates the effect of information on extreme responses. The two sided information is an 
appraisal approach and does not influence the response of the public in either attitudes or behaviour. Bright and Manfredo (1997) using the two sided information appraisal for several natural resources issues, discovered that this was an appropriate approach in that it did not have any negative impact on direction of assessments, rather it minimised biases and extremities of attitudes. The impact of this approach was more based on the importance of the issue to the respondent. If the issues were unimportant to the respondent, the two sided information approach had the impact of moderating extreme positive attitudes and similarly moderated extremely negative attitudes. The results obtained by Millar and Tessar (1986) who were social psychologists working on effects of twosided information and increased knowledge and that of Biek et al. (1996) who worked on role of attitudinal bias on information processing were in sync with that of Bright and Manfredo (1997). Working on offshore marine aquaculture on attitudes towards offshore marine aquaculture, Robertson et al. (2002) examined the effects of the absence or presence of two sided information. Following Robertson et al. (2002) this study classified the groups as discussed above and also identified a control group who were not briefed in respect of the core issue that is being addressed in this research.

\section{Materials and methods}

Two-sided questions approach are special type of questions, used, in many cases, to catch the candidate off guard. They often start with a positive experiential type of question; only then to be followed up quickly with a negative. The objective of two sided information is to inform the public about an issue rather than persuade them into specific attitude and behaviour.

Two categories of respondents were selected for the survey viz., fishers of Dal Lake who are the primary stakeholders of Dal Lake fisheries and fish consumers in Srinagar City. A total of 200 consumers and 100 fishers were randomly selected. Among fish consumers 100 were given two sided information regarding the issue and rest 100 were kept uninformed. Similarly, 50 fishers out of 100 , were given two sided information and 50 were uninformed. The uninformed group in both the cases acted as control. It was found that across all demographic parameters considered for the study, there were no significant differences between the two information groups. The detailed sampling information is given in Fig. 1.

The data were analysed using the Statistical Package for Social Science (SPSS) version 21. Univariate analysis of variance (ANOVA) was used to determine the effect of information and prior familiarity of the issue on attitudes

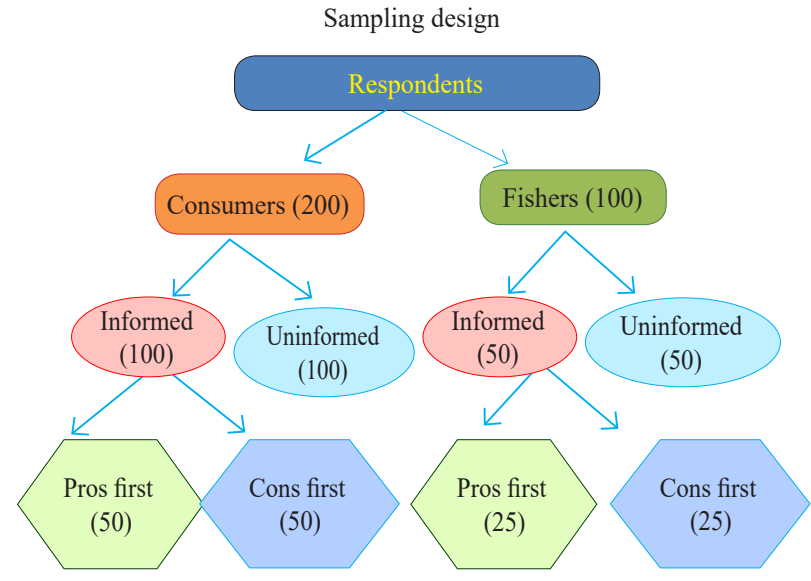

Fig.1. Sampling design

and to investigate the possible interaction effects between the independent variables.

Defining the issue

All the respondents were given prior information regarding the present fisheries status of Dal Lake and how species composition has been changing over the years and why the issue is being taken up as a research problem.

\section{Measure of familiarity}

The attitude questions were requested to be answered by the respondents after providing some basic information about the issue. The respondents were enquired about their familiarity with the actual reasons behind the depletion of local fish species from the lake. This procedure enabled the determination of whether information provided beforehand had any subsidence effect on the changes in attitudes.

Respondents were asked to specify their level of familiarity with the issue, using five-point Likert scale of "Very Unfamiliar", "Unfamiliar", "Unsure", "Familiar" and "Very Familiar". Due to requirement of the analytical tool and less number of responses in the extreme categories, "Very Unfamiliar" and "Very Familiar", categories were fused together so that respondents were segregated into three groups of familiarity, comprising "Not familiar (Very Unfamiliar and Unfamiliar)", "Unsure of familiarity" and "Familiar (Very Familiar and Familiar)".

Immediately after briefing about the issue and prior to attitudinal measurements, information was provided to half of the respondents. The information provided was in the form of twelve statements on the potential advantages and disadvantages of Shizothorax restoration in Dal Lake (Table 1).

In addition, an equal number of advantages and disadvantages of restoration were provided in the information. One half of the participants were presented with pros first and the other half were presented with 
Table 1. Summary structure of two sided information provided to identified respondents

Issue: The composition of fish production in the Dal Lake has been changing with more of carps being landed and less of the Schizothorax, the local species. The local Kashmiri fish (Kashmiri gad) otherwise known as Schizothorax is now disappearing from the plate of the local residents as well as the tourists. This has happened because of the accidental introduction of carps in the lakes in 1950's, increased pollution in the lakes due to tourism, floating vegetable gardens and civic discharges. The Lakes and Waterways Development Authority (LAWDA), Department of Fisheries and other departments are working for the restoration of the Dal Lake. Though the primary objective of the LAWDA and other departments is to restore the lake to promote tourism, this restoration will also help improve fishery in the lake.

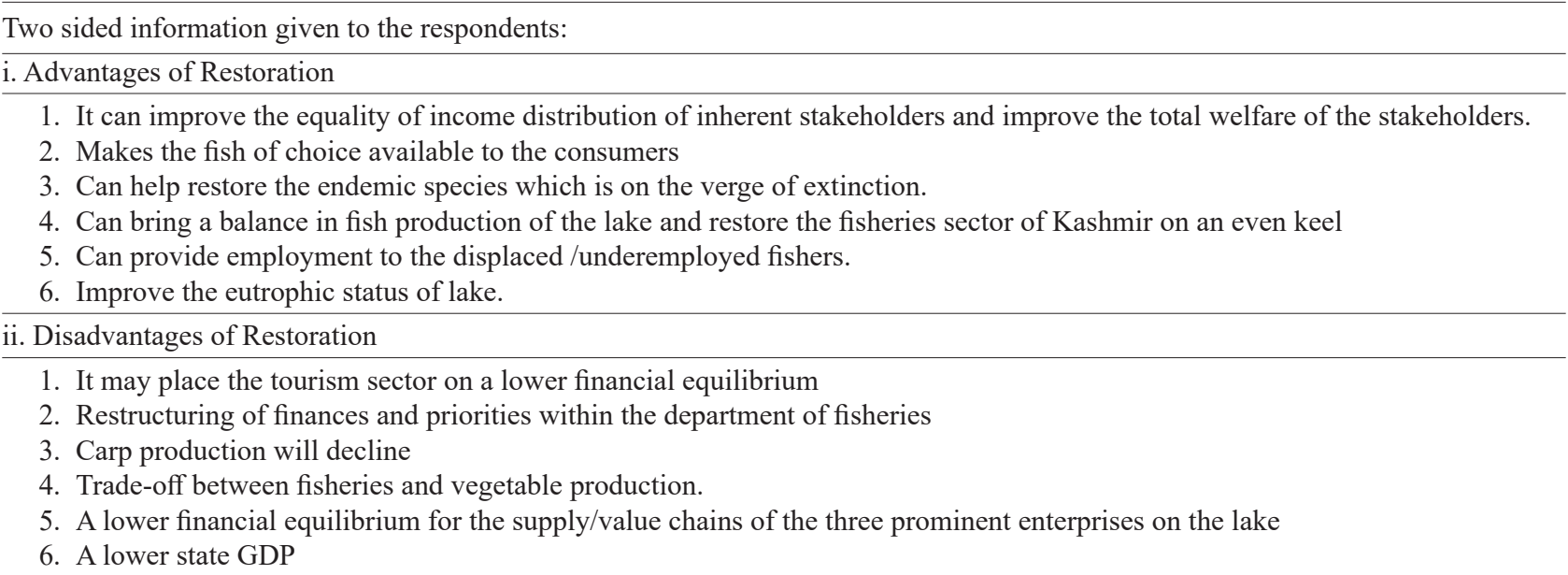

the cons first in order to control for order effects in the information.

\section{Attitude measures}

For developing an attitude scale that focuses on general attitudes of stakeholders towards restoration of Schizothorax fishery, participants were asked to indicate their responses to each of the following questions:

(1) "Do you think promoting sustainability and restoration of Schizothorax fishery in Dal Lake is a GOOD or BAD idea?"

(2) "Do you think developing fisheries in Dal Lake is a BENEFICIAL or HARMFUL idea?"

(3) "Do you think restoring Schizothorax fishery in Dal Lake is a WISE or FOOLISH idea?

A five-point Likert scale ranging from "extremely bad" (or harmful or foolish), "moderately bad" (or harmful or foolish), "neither", "moderately good" (or beneficial or wise) and "extremely good" (or beneficial or wise) was used to measure the responses to these questions. The least favoured response were given a score of one and most favoured responses were given a score of five. To create an index ranging from $1-5$, responses to these three questions were added together and divided by three.

Cronbach's alpha was used to examine reliability of the attitude index. The attitude questions were asked to both the information and no information groups. For the group receiving this information, two-sided information were given followed by attitude questions and for no information group, attitude questions were asked immediately after the familiarity questions.

\section{Results and discussion}

Demographic profile of survey respondents

A summary of the demographic characteristics of survey respondents of both consumers and fishers is provided in Table 2. Almost one-third of respondents were females among consumers and $44 \%$ among fishers and the mean age was 46 and 35 yrs for consumers and fishers respectively. Majority of respondents were sunni muslims among both the stakeholder groups. Average household income was ₹4.5 lakhs per annum in case of consumers and ₹ 34,000 per annum for fishers. Among both the stakeholder groups, almost $50 \%$ of consumers and $39 \%$ fishers consume fish once in a month. Among consumers, more than half of the respondents were employed, $15 \%$ retired and $16.5 \%$ unemployed. Almost two-third of the respondents were graduates and professionals. Rest 19\% were holding masters' degree and around 9\% holding Ph. D degree.

Among fishers, almost half of the participants were illiterate. Highest degree attained was graduation and possessed by only $4 \%$ of the fishers who participated in the survey. Almost one third of the fisher participants had no secondary source of occupation and $13 \%$ were doing 
Table 2. Demographic characteristics of consumers and fishers

\begin{tabular}{|c|c|}
\hline \multicolumn{2}{|l|}{ Consumers } \\
\hline Age & : 46 yr (Mean) \\
\hline Gender & : $66 \%$ Males, $34 \%$ Females \\
\hline Sect & : Sunni: 78\%; Shia: 32\% \\
\hline Average household income & : ₹ 4.5 Lakhs per anum \\
\hline Fish consumption & $\begin{array}{l}: 49 \% \text { - once every month, } \\
24 \% \text { - twice a month }\end{array}$ \\
\hline Highest level of education & $:$ \\
\hline High School & $: 6.5 \%$ \\
\hline B.Sc/B.A & : $34.5 \%$ \\
\hline M.Sc/M.A & $: 18.5 \%$ \\
\hline Ph.D & $: 8.5 \%$ \\
\hline Professional & $: 30.5 \%$ \\
\hline Primary & $: 1.5 \%$ \\
\hline Employment status & $:$ \\
\hline Employed & : $55.5 \%$ \\
\hline Students & $: 13 \%$ \\
\hline Unemployed & : $16.5 \%$ \\
\hline Retired & $: 15 \%$ \\
\hline \multicolumn{2}{|l|}{ Fishers } \\
\hline$\overline{\text { Age }}$ & : 35yrs (Mean) \\
\hline Gender & : $54 \%$ Males, $44 \%$ Female \\
\hline Sect & : Sunni: 72\%; Shia: 38\% \\
\hline Average household income & : ₹ 34,000 per annum \\
\hline Fish consumption & $\begin{array}{l}: 39 \% \text { - once every month, } \\
28 \% \text { - twice a month }\end{array}$ \\
\hline \multicolumn{2}{|l|}{ Highest level of education } \\
\hline Illiterate & $: 52 \%$ \\
\hline Primary & $: 8 \%$ \\
\hline Middle & $: 20 \%$ \\
\hline High School & $: 16 \%$ \\
\hline Graduate & $: 4 \%$ \\
\hline
\end{tabular}

labour work and $19 \%$ were involved in marketing related activities as secondary source of income.

This experiment on providing information to one group and none to the other, enabled assessment on a broader perspective and removed bias in the responses. The comparative analysis showed that the two groups, consumers and fishers had similar socio-demographic characteristics.

\section{Respondents' familiarity with the problem}

Familiarity was used to get an insight on how aware respondents were, about depletion of indigenous species from the Dal Lake. Among consumers, 27.5\% were unfamiliar while $42 \%$ were familiar with the issue. The remaining respondents, approximately $30.5 \%$, indicated that they were unsure about their familiarity with the issue. Among fishers, majority of the participants (66\%) were familiar with the issue, $14 \%$ unfamiliar and $20 \%$ were unsure about the issue. The mean familiarity score for consumers and fishers was 2.15 and 2.52 respectively on a five point Likert scale and there was no significant difference in familiarity between the no information and information groups for both fishers and consumers separately. The respondents who supported restoration of Schizothorax were those, who were familiar with the depletion of this species. In case of consumers, the responses were relatively muted owing to their lack of familiarity with the issue of the need for restoration. The attitude of fishers did not have any impact on familiarity since they earnestly wanted the Dal fisheries to be restored.

Attitudes towards restoration of Schizothorax fishery in Dal Lake

Attitudinal scale testing of stakeholders towards sustainability and restoration of (Dal) Lake fisheries in India has not been studied so far. Some work centered towards the development, encroachments and socio-economic valuation of lakes are available (Wani et al., 2013; Amin et al., 2014; Qayoom et al., 2016). This study represents an inceptive attempt at developing an attitude scale that focuses on general attitudes of stakeholders towards restoration of Schizothorax fishery. Cronbach's alpha is a measure of internal consistency, that is, how closely related a set of items are as a group. It is considered to be a measure of scale reliability. A "high" value for alpha does not imply that the measure is unidimensional. It can be written as a function of the number of test items and the average inter-correlation among the items. The attitude index having Cronbach's alpha value close to 1 , strongly suggests that the items in the index are measuring the same thing (Vogt, 1999). This enhances the validity of the attitude measure and has been investigated to provide reliable measure of attitudes in many social/psychological research on attitudes (Fishbein and Ajzen, 1975).

Majority of the respondents had positive assessment of Schizothorax restoration. Nearly $60 \%$ of the consumers and $80 \%$ of fishers felt that restoring Schizothorax fishery was a GOOD idea (mean= 3.32 and 4.12 on a scale of 1 to 5). About $38 \%$ of consumers and $51 \%$ fishers felt that Schizothorax restoration was a WISE idea $(\mathrm{m}=3.29$ and 4.18$)$ and $38 \%$ consumers and $48 \%$ fishers felt it was BENEFICIAL too (mean $=3.33$ and 4.22 ). The Cronbach's alpha value revealed that the index of the three attitudinal questions was highly reliable at $\alpha=0.96$ and 0.98 for consumers and fishers respectively with a mean attitude score of 4.16 and 3.32 on a 5-point scale (Table 3). The relationship between familiarity with the issue of Schizothorax depletion and attitude towards its restoration was significant in case of consumers only.

Respondents among consumers who were familiar with Schizothorax depletion, held significantly more 
Table 3. Reliability of attitudinal questions

\begin{tabular}{lllllll}
\hline Attitude & Consumers & Mean & Cronbach Alpha index & Fishers & Mean & Cronbach Alpha index \\
\hline Good Idea & $60 \%$ & 3.32 & & $80 \%$ & 4.12 & \\
Wise Idea & $38 \%$ & 3.29 & 0.98 & $51 \%$ & 4.18 & 0.96 \\
Beneficial Idea & $38 \%$ & 3.33 & & $48 \%$ & 4.22 & \\
\hline
\end{tabular}

positive attitude towards its development than respondents who reported being unfamiliar with the issue or were unsure of their familiarity, whereas there was no effect of familiarity on the attitude of fishers since by any means they want Dal fisheries to be restored (Table 4).

\section{Impact of information on attitudes}

Table 5 shows the results of univariate ANOVA which suggest that the fishers were influenced in favour of restoration of Schizothorax fishery based on the information obtained and there was no significant effect of information on responses of consumers. It was found that information provided about Schizothorax restoration had resulted in a less positive effect on the attitude of the respondents compared to the no information group. The fact that the uninformed fishers of the Dal Lake expressed a significant desire for the restoration of the Schizothorax fishery than those fishers who were reappraised about the need, does not in any way undermine the methodology, since the fishers as a group were well aware of the issue and this reappraisal might not have made much difference to their attitude.

Table 6 gives the interaction effect of information and familiarity that emerged from univariate ANOVA on attitudes towards restoration of Schizothorax fishery.
Excluding the consumers who were already familiar with the issue, the information provided seemed to have a positive effect on attitudes towards the restoration process. Magnitude of the positive effect of information was greater for the fishers who were unsure and unfamiliar with the issue than those who were familiar. This can be attributed to the fact that fishers are primary stakeholders and will be benefitted most with the restoration of Schizothorax fishery and hence for those who were unaware about the issue, the interactive effect of familiarity and information had a significant positive effect on attitudes. It can be seen that providing information to the fishers had significantly improved their attitude towards restoration of Schizothorax fishery, since the mean values can be seen to be improved after providing information on the issue.

The entire analysis captured the effect of information on the attitudes of stakeholders for restoration of Schizothorax fishery in Dal Lake. Results of the analyses clearly indicate that fishers who are the primary stakeholders on the lake held a very positive attitude towards restoration of Schizothorax fishery in the lake than consumers, since they were concerned only about fisheries. Therefore their opinions were biased and self-centric rather than social welfare centric. The study also revealed the edge that was given to the respondents

Table 4. Bivariate relationship between familiarity and attitudes of consumers and fishers

\begin{tabular}{llllllll}
\hline Level of familiarity & $\begin{array}{l}\text { Consumers mean attitude score } \\
\text { (based on scale from 1 to 5) }\end{array}$ & F-value & Sig. & $\begin{array}{l}\text { Fishers mean attitude score } \\
\text { (based on scale from 1 to 5) }\end{array}$ & F-Value & Sig. \\
\hline Not familiar & 2.84 & 23.36 & 0.000 & 3.83 & 2.09 & 0.12 \\
\hline
\end{tabular}

Table 5. Effect of information on attitudes of consumers and fishers towards Schizothorax fishery restoration in Dal Lake

\begin{tabular}{lllllll}
\hline Group & Consumers attitude score (Mean) & F-Value & Sig. & Fishers attitude score (Mean) & F-Value & Sig. \\
\hline Information & 3.30 & & & 3.84 & & \\
No Information & 3.34 & 0.06 & 0.79 & 4.46 & 22.13 & 0.000 \\
\hline
\end{tabular}

Table 6. Estimated marginal means of attitude for consumers and fishers

\begin{tabular}{|c|c|c|c|c|c|c|c|c|}
\hline & \multicolumn{2}{|c|}{ Consumers } & & & \multicolumn{2}{|c|}{ Fishers } & & \\
\hline & No Information & Information & & & No Information & Information & & \\
\hline $\begin{array}{l}\text { Level of } \\
\text { Familiarity }\end{array}$ & Mean & Mean & F-Value & Sig. & Mean & Mean & F-Value & Sig. \\
\hline Not Familiar & 2.34 & 3.33 & 28.11 & 0.001 & 3.11 & 4.37 & 8.365 & 0.000 \\
\hline Unsure & 2.80 & 3.32 & & & 3.28 & 4.61 & & \\
\hline Familiar & 4.28 & 3.35 & & & 4.10 & 4.41 & & \\
\hline
\end{tabular}


resulting from a priori information delivery. This enabled educated judgement vis-à-vis summary judgement based on hearsay information. The results have meaningful and valid implications stating that restoring Schizothorax fishery is a beneficial idea at least for fishers since they derive their income directly from it and it is a wise and good idea for consumers who relish the fish as a delicacy.

The results lead to the conclusions that effective communication is very important between the institutions concerned with restoration of Schizothorax fishery and specific stakeholder groups. The results also reveal that provision of information has significantly improved the attitude of stakeholders towards restoration. The methodology helps in making an assessment of what the public knows about restoration of Schizothorax fishery prior to developing restoration campaigns. The effort also gives an indication of the extent to which the respondents pay attention to or search for information on an issue in the first instance.

\section{Acknowledgements}

The authors are grateful to Dr. T. Mohapatra, Secretary, DARE and Director General, ICAR, New Delhi and Dr. Gopal Krishna, Director/Vice Chancellor, ICAR-CIFE, Mumbai, for constant encouragement and support during the entire period of this work. The authors are also thankful to the anonymous reviewer for valuable comments and suggestions which further helped to improve the paper.

\section{References}

Amin Arshad, Fazal, S., Mujtaba, A. and Singh, S. K. 2014. Effects of land transformation on water quality of Dal Lake, Srinagar, India. J. Ind. Soc. of Remote Sens.,42(1): 119-128.

Biek, M.. Wood, W. and Chaiken, S. 1996. Working knowledge, cognitive processing, and attitudes: on the determinants of bias. Pers. Soc. Psychol. Bull., 22(6): 547-556.
Bright, A. D. and Manfredo, M. J. 1997. The influence of balanced information on attitudes towards natural resource issues. Soc. Nat. Res., 10: 469-483.

Fishbein, M. and Ajzen, I. 1975. Belief, attitude, intention and behaviour: An introduction to theory and reading. Addison-Wesley Publishing Co., Reading, MA.

Millar, M. G. and Tesser, A. 1986. Thought-induced attitude change: the effects of schema structure and commitment. J. Pers. Soc. Psychol., 51: 259-269.

Naik Gulzar, Rangil, G., Rashid, M. and Bhat, F. A . 2015. Food and feeding habits of Cyprinus carpio var. communis: A reason that decline Schizothoracine fish production from Dal Lake of Kashmir Valley. Fish. Aquacul. J., 6(4): 12-19.

Qayoom Imtiyaz, Nasir Hussain, Tariq, A., Bhat Masood, H., Balkhi Bilal and Bhat, A. 2016. A study of socio-economic status of fisher communities in District Srinagar of Jammu \& Kashmir. Ind. J. Econ. Dev., 4(7): 2016.

Qureshi, N. W. 2013. Contingent valuation of multiple stakeholders responses to fish production in major lakes of Kashmir, M.F.Sc. Thesis, Central Institute of Fisheries Education, Mumbai.

Robertson Robert A., Erika L. Carlsen and Alan Bright. 2002. Effect of information on attitudes towards offshore marine finfish aquaculture development in northern New England. Aquacult. Econ. Manage., 6(1/2): 2002.

Vogt, P. W. 1999. Dictionary of statistics and methodology: A non-technical guide for the social sciences. $2^{\text {nd }}$ edn. Sage Publications, Thousand Oaks.

Wani, M. H., Baba, S. H., Shahid Yousuf, Mir, S. A. and Shaheen, F. A. 2013. Economic valuation and sustainability of Dal Lake ecosystem in Jammu and Kashmir. In: Nautiyal, S., Rao, K., Kaechele, H., Raju, K. and Schaldach, R. (Eds.), Knowledge systems of societies for adaptation and mitigation of impacts of climate change. Environmental Science and Engineering, Springer, Berlin, Heidelberg, p. 95-118. 